\title{
The Diagnosis Odyssey of Disorders of Sexual Development: A Case Report of 9p22-pter Deletion Syndrome without Trigonocephaly
}

DOI: $10.46932 /$ sfjdv3n1-059

Received in: Jan 30st, 2021

Accepted in: Feb 1th, 2022

\author{
Isabel Alicia Loya Aguilar \\ Third year Resident Doctor in Clinical Genetics \\ Centro Médico Nacional 20 de Noviembre ISSSTE \\ San Lorenzo 502, building E, Lobby col. Del Valle Mexico City. Zip Code 03200 \\ E-mail: isaloya.md@gmail.com \\ María del Carmen Chima-Galán \\ Chief of Clinical Genetics Department \\ Clinical Geneticist \\ Centro Médico Nacional 20 de Noviembre ISSSTE \\ San Lorenzo 502, building E, Lobby col. Del Valle Mexico City. Zip Code 03200 \\ E-mail:carmenchimg@yahoo.com.mx \\ Yuritzi Santillán Hernández \\ Clinical Geneticist \\ Centro Médico Nacional 20 de Noviembre ISSSTE \\ San Lorenzo 502, building E, Lobby col. Del Valle Mexico City. Zip Code 03200 \\ E-mail:yurisan@yahoo.com

\section{Liliana García-Ortiz} \\ Clinical Geneticist \\ Centro Médico Nacional 20 de Noviembre ISSSTE \\ San Lorenzo 502, building E, Lobby col. Del Valle Mexico City. Zip Code 03200 \\ E-mail: garortiz@yahoo.com
}

\begin{abstract}
Introduction: The 9p deletion syndrome is characterized for the presence of trigonocephaly, dysmorphism, genitourinary anomalies and developmental delay. The clinical synopsis depends on the size of the deletion. Clinical Case: 14 month old infant with disorder of sexual development, developmental delay and dysmorphisms without trigonocephaly. Karyotype with 46,XY,del(9p22)(pter). Discussion: Sexual development disorders are very hard to diagnose, in their primary approach a karyotype is essential, most disorders can be diagnosed through this technique, other studies are also needed. Within these disorders $9 \mathrm{p}$ deletion syndrome is the less common, there are around 700 cases reported in the world, therefore it is important to keep contributing to the phenotype-genotype. This patient does not have trigonocephaly which bears the question of what other mechanisms are involved besides haploinsufficiency.
\end{abstract}

Keywords: de19p(22), Disorders of Sexual Development, trigonocephaly. 


\section{INTRODUCTION}

9p Deletion syndrome (Online Mendelian Inheritance in Man [OMIM]:\# 158170) is a genomic disorder with an incidence is less than 1/100 000 000. It is characterized by the presence of trigonocephaly, flat occipital region, low posterior hairline, low set ears, prominent forehead, arched eyebrows, hypertelorism, short palpebral fissures, epicanthus, depressed nasal bridge, anteverted nostrils, long philtrum, thin upper lip, dental crowding, micrognathia, short neck and very long phalanges. Other manifestations include cardiac defects, inguinal hernia, omphalocele, and disorders of sexual development. (Huret et al., 1988)

In 2 thirds the deletion is de novo because of defective paternal or maternal meiosis and one third is hereditary due to balanced chromosomal rearrangements in either parent, mainly, chromosomal translocations. (Quinonez et al., 2013)

Alfi et al. reported the first case of 9p deletion syndrome (Alfi et al., 1973) the clinical characteristics that they described are the consensus phenotype today. To this date around 700 cases have been reported.

The phenotype is variable depending in the size of the deletion, there are several studies comparing breakpoints in different patients with 9p deletion syndrome and they conclude that p22-p24 is the critical region involving 4-6Mb (Sams et al., 2022) Most patients have a pure terminal deletion in the shor arm of chromosome 9 but some have chromosomal rearrangements that involve the critical region. Shimojima and Yamamoto (Shimojima \& Yamamoto, 2009) postulated CER1 (OMIM\# 603777), TYRP1 (OMIM\# 115501) and PTPRD (OMIM\# 601598) as the genes for the consensus phenotype which are localized in p22-p24 (Faas et al., 2007; Mitsui et al., 2013; Shimojima \& Yamamoto, 2009). Other candidate genes are DMRT1 (MIM: 602424) and DMRT3 (MIM: 614754) associated with disorders of sexual development, FREM1 (MIM: 608944) for trigonocephaly, FOXD4 (MIM: 601092) for speech and language disorders, DOCK8 (MIM: 611432) GLDC (MIM: 238300), VLDLR (MIM: 192977), and ZDHHC21 (MIM: 614605) in intellectual deficit and seizures, CBWD1 (MIM: 611078) cobalamin deficiency and KANKI (MIM: 607704) associated with autism and cerebral palsy. (Sams et al., 2022) (figure. 1)

We present a sporadic case of $9 p$ deletion syndrome whose first approach was through the presence of Disorders of Sexual Development (DSD) and differs from the consensus phenotype with no trigonocephaly. 


\section{CASE REPORT}

A 15 month old infant is referred to the genetics clinic due to DSD. There is no family history related to the present condition. He is product of the third gestation, of non-consanguineous parents, mother is 38 years and father is 31 years at moment of birth. Pregnancy was referred as normal and without any complications. Birthweight was $3500 \mathrm{~g}$ and length of $56 \mathrm{~cm}$ the newborn is catalogued as a female baby and was released from the hospital within 24 hours of birth. At 40 days of birth the pediatrician observed clitoromegaly and supected DSD, and indicated a pelvic ultrasound showing no evidence of uterus and ovaries.

The clinical examination performed by the genetic department revealed that the infant had a notorious developmental delayed with head support at 12 months, seating by himself at 14 months, standing and walking still absent. In physical examination we find no cranial abnormalities, prominent forehead, arched eyebrows, broad and depressed nasal bridge, short columnella, thin upper lip and micrognathia. Genitals with micro pennis, proximal interscrotal hypospadias, stage IV of Prader scale and bilateral cryptorchidism, gonads are palpable in the inguinal canal (fig. 2A and 2B).

Due to the presence of DSD a Karyotype is ordered with the following formula: 46,XYdel(9)(p22)(pter) as seen in figures $3 \mathrm{~A}$ and $3 \mathrm{~B}$.

As part of the diagnosis approach a karyotype is made for both parents with the normal results for the father $(46, X Y)$ and mother $(46, X X$.

The hormonal profile was normal.

To this date the patient is in multidisciplinary follow-up with general pediatrics, pediatric surgery and pediatric endocrinology.

\section{DISCUSSION}

Sexual development disorders are difficult to diagnose, in their primary approach a karyotype is essential, most disorders can be diagnosed through this technique, other studies are also needed. Within these disorders 9p deletion syndrome is the less common, there are around 700 cases reported in the world, therefore it is important to keep contributing to the phenotype-genotype.

It has been postulated that the haploinsufficiency of the genes involved combined with other genetic defects are responsible for the consensus phenotype. This patient has different clinical characteristics previously reported in the literature by Huret et al. (table 1). He also presents a bigger deletion from p22-pter, involving the genes depicted in figure 1; therefore we could expect a greater intellectual deficit, for this reason it is important that in his follow-up a psychometric evaluation is made by the age of 4 years old as well development assessment in every consult. The genes in this region are 
also involved in seizures which by the moment are not present in the patient but we cannot rule out that this won't happen in the future so a neurological assessment should be made as well with EEG and MRI, $C B W D 1$ is also in this region a test to verify a cobalamin deficiency can also be made in case any clinical symptoms related to this disorder start to be notorious.

The absence of trigonocephaly in our patient supports the theory that the loss of just one allele of the FREMI is not sufficient for the characteristic to be present, for this reason there should be more research involving other genetic and epigenetic mechanisms.

The DSD in this infant supports the hypothesis that de DRMT1 and DMRT3 genes regulate male sexual development even when there had been some reports of cases with DSD and no deletion of these genes.

In this patients a microarray study should be performed to define the size of the deletion and the exact breakpoints to keep contributing data to the ohenotype-genotype.

This patients have a higher risk of gonadoblastoma (15-20\%) because in this region there are some tumor suppressor genes. [Huret et al., 1988; Mc Donald et al., 1997; Muroya et al., 2000; Livadas et al., 2003].

\section{CONCLUSION}

When a DSD patient is detected by the pediatrician or any other first contact service it is always important to refer the patient to the genetics service. As part of the diagnosis approach a karyotype should be performed to classify the DSD, in most cases it will be abnormal; other studies such as hormonal levels, pelvic ultrasound and others should be performed.

We consider of great importance the close follow-up with the help of the pediatrics service, pediatric surgery, endocrinologic service and pediatric neurology if necessary. In our patient for the quantity of genes deleted we suspect a strong intellectual deficit is present and disorders of speech and language will develop this is why a psychometric evaluation should be performed when the right age is reached as well as language therapy specially with a model like the proposed by Vivero Riquelme in her work " Proposal for individual intervention for language development in early childhood education“ (Riquelme, 2022) since this model has a personal approach depending in the child's need. 
Fig.1: Chr9 and genes involved in 9p deletion syndrome

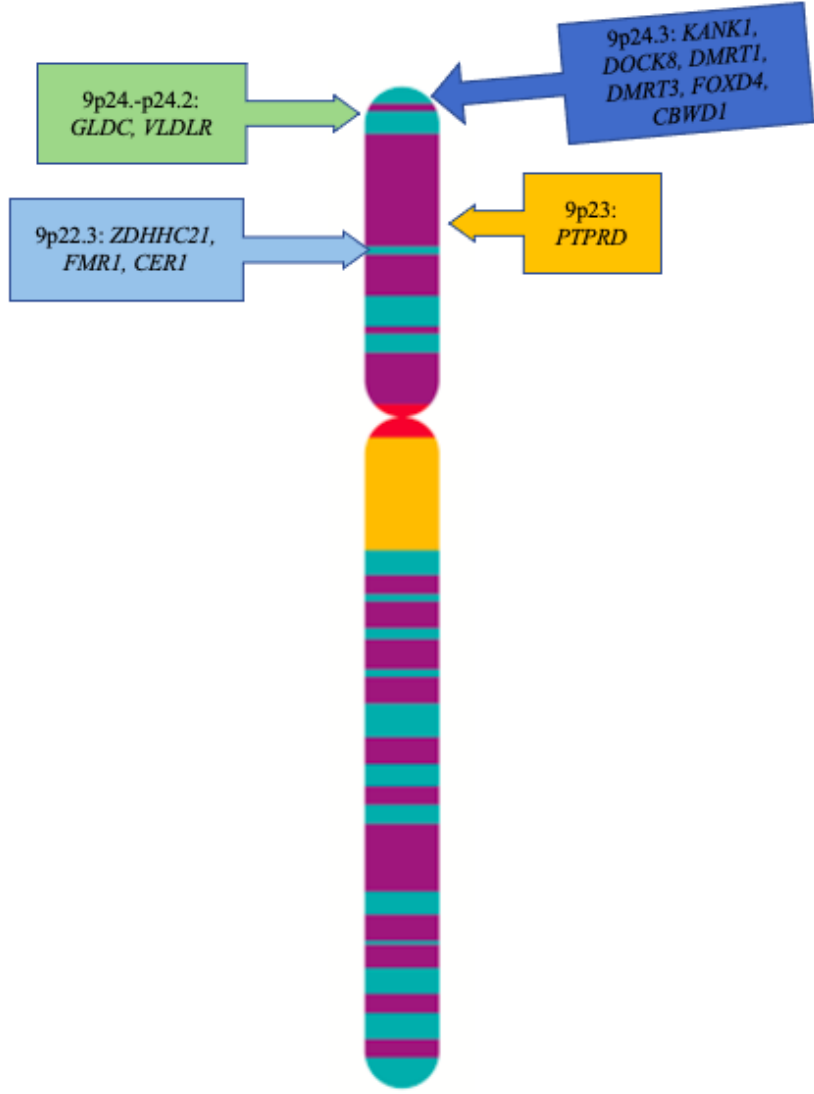

Fig. 2A

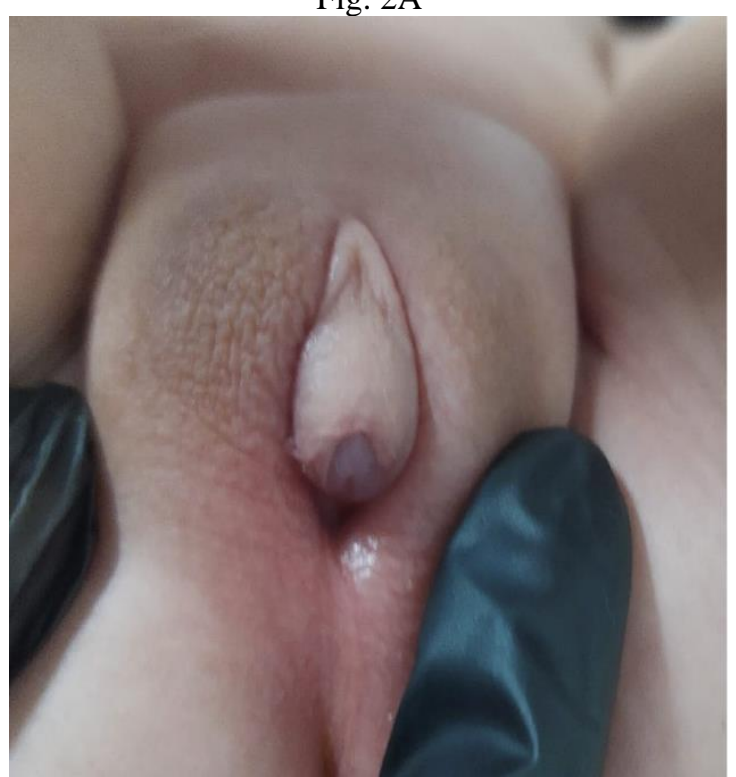


Fig. 2B

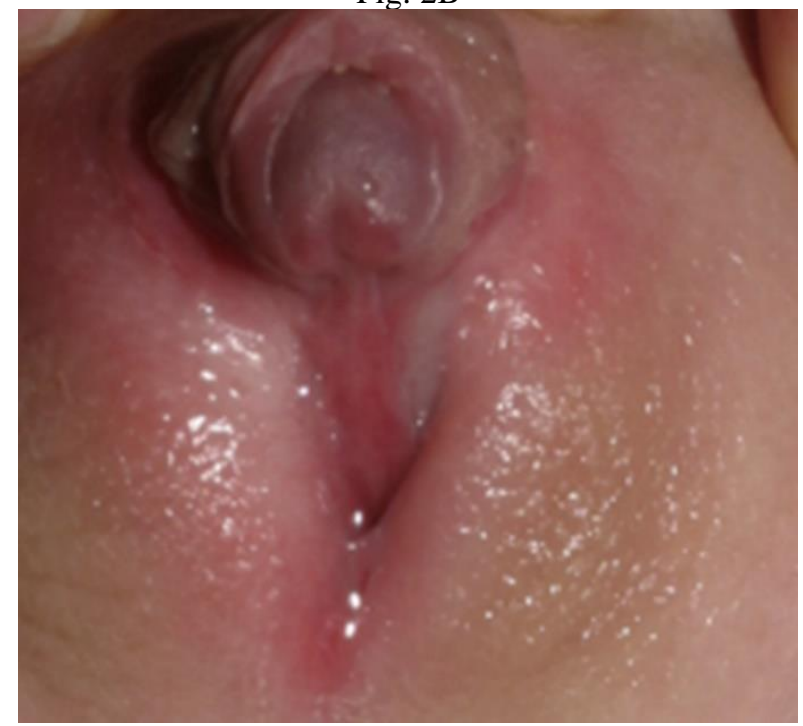

Fig. 3A: Karyotype in peripheral lymphocytes of the patient: 46,XYdel(9)(p22)(pter)
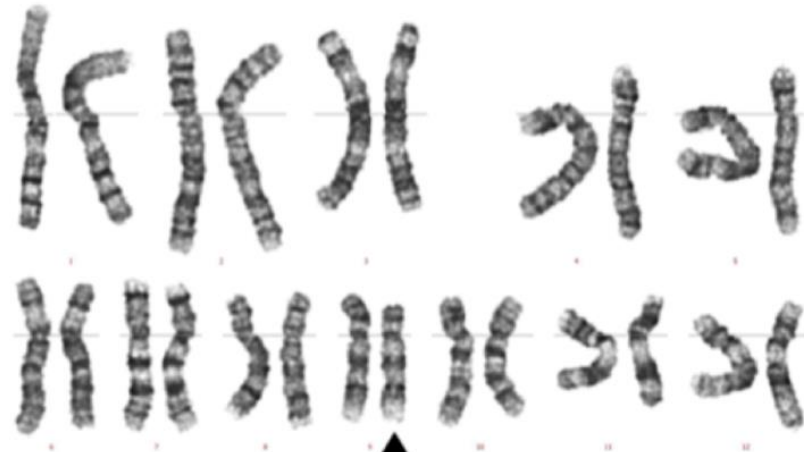

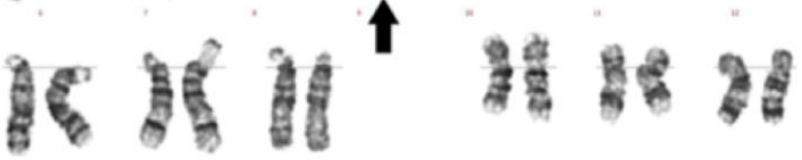

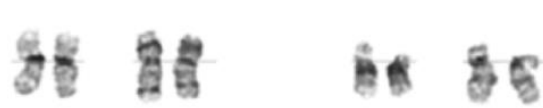

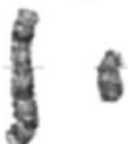

Fig. 3B: 9p deletion idiogram

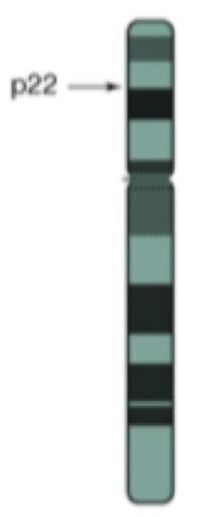

9nl



del(9)

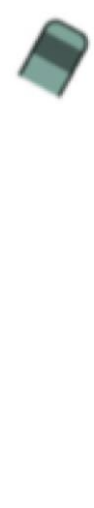

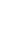

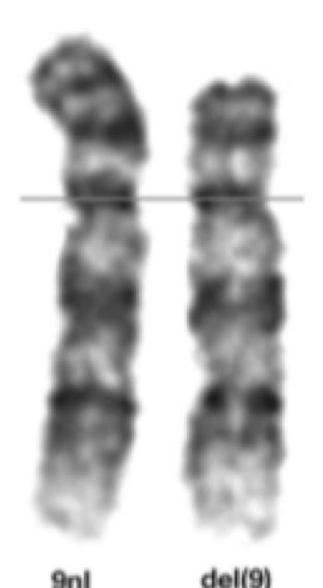

9nl del(9) 
Table 1. phenptipic characteristics of the patient in contrast with those found in the study of Huret and cols.

\begin{tabular}{|l|l|l|}
\hline Clinical characteristics & Huret y cols. & Patient \\
\hline Developmental delay & $100 \%$ & $\mathbf{X}$ \\
\hline Trigonocephaly & $100 \%$ & \\
\hline Prominent forehead & $100 \%$ & $\mathbf{X}$ \\
\hline Arched eyebrows & $\mathbf{8 1 . 4 \%}$ & $\mathbf{X}$ \\
\hline Upslated palpebral fissures & $\mathbf{3 3 . 3 \%}$ & \\
\hline Epicanthus & $\mathbf{7 6 \%}$ & \\
\hline Midface hypoplasia & $\mathbf{8 6 \%}$ & \\
\hline Depressed nasal bridge & $\mathbf{9 6 . 4 \%}$ & $\mathbf{X}$ \\
\hline Anteverted nostrils & $\mathbf{9 3 . 7 \%}$ & \\
\hline Long philtrum & $\mathbf{1 0 0 \%}$ & $\mathbf{X}$ \\
\hline Micrognathia & $\mathbf{8 6 . 6 \%}$ & $\mathbf{X}$ \\
\hline Thin upper lip & & $\mathbf{X}$ \\
\hline Genitourinary anomalies & $41.6 \%$ & $\mathbf{X}$ \\
\hline
\end{tabular}




\section{BIBLIOGRAPHY}

Alfi, O., Donnell, G. N., Crandall, B. F., Derencsenyi, A., \& Menon, R. (1973). Deletion of the short arm of chromosome no.9 (46,9p-): A new deletion syndrome. Annales De Genetique, 16(1), 17-22.

Faas, B. H. W., de Leeuw, N., Mieloo, H., Bruinenberg, J., \& de Vries, B. B. A. (2007). Further refinement of the candidate region for monosomy 9p syndrome. American Journal of Medical Genetics. Part A, 143A(19), 2353-2356. https://doi.org/10.1002/ajmg.a.31961

Huret, J. L., Leonard, C., Forestier, B., Rethore, M. O., \& Lejeune, J. (1988). Eleven new cases of del(9p) and features from 80 cases. Journal of Medical Genetics, 25(11), 741-749. https://doi.org/10.1136/jmg.25.11.741

Mitsui, N., Shimizu, K., Nishimoto, H., Mochizuki, H., Iida, M., \& Ohashi, H. (2013). Patient with terminal $9 \mathrm{Mb}$ deletion of chromosome 9p: Refining the critical region for 9p monosomy syndrome with trigonocephaly: 9p monosomy critical region. Congenital Anomalies, 53(1), 49-53. https://doi.org/10.1111/j.1741-4520.2012.00362.x

Quinonez, S. C., Park, J. M., Rabah, R., Owens, K. M., Yashar, B. M., Glover, T. W., \& Keegan, C. E. (2013). 9p partial monosomy and disorders of sex development: Review and postulation of a pathogenetic mechanism. American Journal of Medical Genetics Part A, 161(8), 1882-1896. https://doi.org/10.1002/ajmg.a.36018

Riquelme, M. D. C. V. (2022). Propuesta de intervención individual para el desarrollo del lenguaje en educación infantil: Proposal for individual intervention for language development in early childhood education. South Florida Journal of Development, 3(1), 124-136. https://doi.org/10.46932/sfjdv3n1-009

Sams, E. I., Ng, J. K., Tate, V., Claire Hou, Y.-C., Cao, Y., Antonacci-Fulton, L., Belhassan, K., Neidich, J., Mitra, R. D., Cole, F. S., Dickson, P., Milbrandt, J., \& Turner, T. N. (2022). From karyotypes to precision genomics in 9p deletion and duplication syndromes. Human Genetics and Genomics Advances, 3(1), 100081. https://doi.org/10.1016/j.xhgg.2021.100081

Shimojima, K., \& Yamamoto, T. (2009). Investigation of the candidate region for trigonocephaly in a patient with monosomy 9p syndrome using array-CGH. American Journal of Medical Genetics. Part A, 149A(5), 1076-1080. https://doi.org/10.1002/ajmg.a.32783 